\title{
Who needs blood? The flip side of blood conservation
}

\author{
Victor A. Ferraris, MD, PhD
}

From the University of Kentucky, Lexington, Ky.

Disclosures: Author has nothing to disclose with regard to commercial support.

Received for publication Oct 14, 2016; accepted for publication Oct 17, 2016; available ahead of print Nov 4, 2016.

Address for reprints: Victor A. Ferraris, MD, PhD, A301 Kentucky Clinic, 740 South Limestone, Lexington, KY 40536-0284 (E-mail: Ferraris@earthlink.net).

J Thorac Cardiovasc Surg 2017;153:606-9

$0022-5223 / \$ 36.00$

Copyright $(2016$ by The American Association for Thoracic Surgery

http://dx.doi.org/10.1016/j.jtcvs.2016.10.031

Blood transfusion associated with cardiac operations carries a morbidity risk. Likewise, worse outcomes occur in patients with significant perioperative anemia. Responses to anemia during cardiac procedures must be balanced against the risks of transfusion. Extremes of perioperative transfusion and preoperative anemia are 2 ends of a spectrum of adverse surgical outcomes (Figure 1). ${ }^{1,2}$ Reasonable goals of any operation, especially cardiac procedures, include limiting bleeding and limiting transfusion. Collectively, these 2 components represent direct outcome measures of a term loosely referred to as "blood conservation." The term "blood conservation" encompasses multiple interventions with varying degrees of evidence to support their use (Table 1). ${ }^{3,4}$ In this issue of the Journal, Ad and colleagues $^{5}$ describe a collaborative multidisciplinary blood conservation effort that used some of the interventions described in Table 1. Their efforts were undertaken over a 3- to 4-year period and, on the surface, resulted in cost savings and improved surgical outcomes. For the most part, the patients in this study were low to moderate risk for adverse outcomes. There were few emergency operations. The additive European System for Cardiac Operative Risk Evaluations were low. Average cardiopulmonary bypass times were modest. Ejection fractions were nearly normal. Because of the study design (ie, before and after an intervention), Ad and colleagues ${ }^{5}$ acknowledge a significant possibility of bias in the study outcomes. It is entirely possible that increased emphasis on bleeding and blood transfusion affected all team members independently of institution of blood conservation interventions. The subtle changes in care patterns related to increased emphasis on blood conservation may have altered behavior by all team members, resulting in improved bleeding outcomes. Regardless of the reasons for the improvement in outcomes, the benefits to patients are obvious. A secondary benefit accrues to the institution, for which Ad and colleagues ${ }^{5}$ estimated more than a $\$ 3.75$ million yearly savings from improved outcomes.

A look at the entire spectrum of transfusion in all patients undergoing cardiac operations gives a different picture than that of the study groups described by Ad and colleagues. ${ }^{5}$

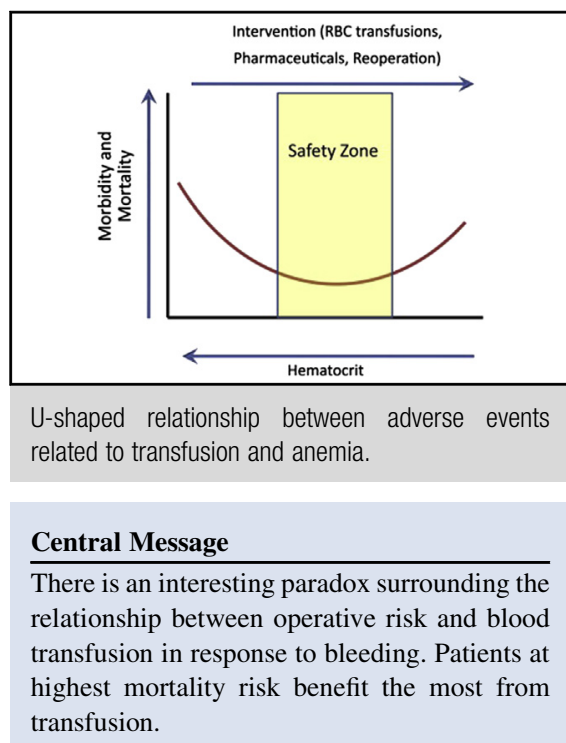

See Article page 597.

The distribution of blood transfusion and bleeding in cardiac surgical patients suggests that approximately $80 \%$ of blood product transfusions occur in approximately $10 \%$ to $20 \%$ of patients (Figure 2). ${ }^{4}$ Members of this group are the "high-end users" of the blood bank and are different than those described by Ad and colleagues. ${ }^{5}$ Figure 2 is a graphic representation of this typical distribution curve that includes all patients undergoing cardiac procedures. The blood conservation interventions described by Ad and colleagues $^{5}$ and those listed in Table 1 are certainly applicable to all patients undergoing cardiac operations, not just low- or moderate-risk patients described by these authors. However, these statements are not meant to minimize the benefits of transfusion. Every experienced surgeon knows a patient whose life was saved by transfusions. Most commonly, this occurs in the setting of massive transfusion with associated massive blood loss. There is overwhelming evidence that patients with massive bleeding need massive transfusion. ${ }^{6,7}$ Transfusion is lifesaving in certain patients, and these patients are least likely to benefit from the full spectrum of blood conservation measures. Transfusion in these situations is lifesaving and provides clear benefit in select patients. ${ }^{8}$

There is an interesting paradox surrounding the relationship between operative risk and blood transfusion in response to bleeding. Observational data suggest that patients at highest mortality risk benefit the most from transfusion in critical situations, whereas those at lower risk 


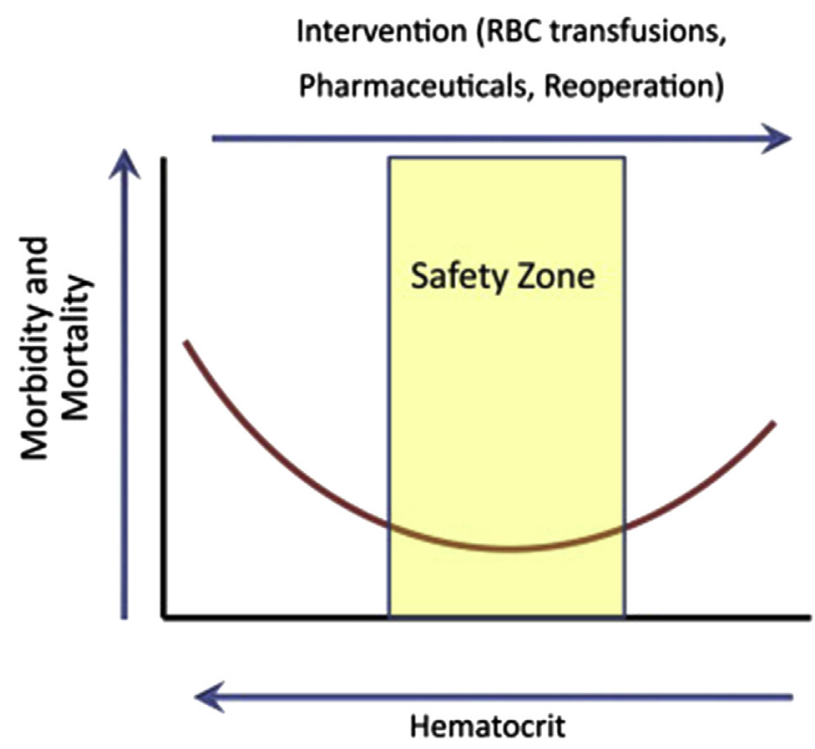

FIGURE 1. Pictorial representation of a U-shaped relationship that exists between adverse events related to degree of anemia on the left and degree of intervention on the right. The "safety zone" at the bottom of the curve reflects a balance between tolerable anemia and interventions to correct anemia. ${ }^{2} R B C$, Red blood cell.

have substantially increased morbidity and mortality associated with blood transfusion (Figure 3). ${ }^{9,10}$ Surgical patients with clearly defined benefits from transfusion comprise a minority of all patients who receive a transfusion. The most common type of blood transfusion

TABLE 1. Multimodality blood management protocol ${ }^{4}$

\section{Preoperative interventions}

Establish blood management team and designate "champion"

Weekly team meetings for protocol development

Account for catheter laboratory blood loss

Evaluate and treat preoperative anemia (role for short course of $\mathrm{EPO} / \mathrm{FeSO} 4)$

Minimize emergency procedures

Correct platelet and coagulation abnormalities if possible

Intraoperative interventions

Minimally invasive procedures if possible mini-CPB circuits

Retrograde autologous priming

Aggressive blood salvage (eg, rinse sponges, minimize cardiotomy use)

Minimize crystalloid administration

Inotropes instead of volume resuscitation

Aggressive hemostasis including topical agents

Antifibrinolytic therapy

Rewarm to normal temperatures

Careful heparin/protamine management

Postoperative care micro blood draws

Minimize (protocolize) blood draws

Early extubation and ambulation

Low transfusion threshold accepted by all providers $(\mathrm{Hgb}=7-8 \mathrm{~g} / \mathrm{dL})$ Iron supplementation with EPO

$E P O$, Erythropoietin; $\mathrm{FeSO}$, iron sulfate; $\mathrm{CPB}$, cardiopulmonary bypass; $\mathrm{Hgb}$, hemoglobin.

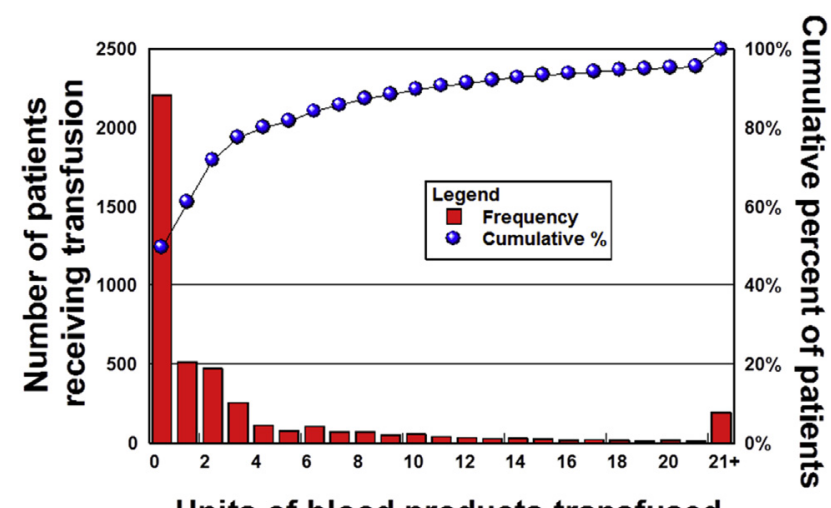

FIGURE 2. Pareto diagram of typical blood product transfusion in a broad spectrum of patients undergoing cardiac procedures.

in cardiac surgical patients is 1 or 2 units of packed red blood cells. The benefit of transfusion of a single unit of packed red blood cells is uncertain and may cause more harm than benefit. ${ }^{11}$ This complex relationship suggests that perioperative blood transfusion is a balance between the 2 extremes of a few patients who clearly benefit from transfusion and a few others who may experience harm from minimal amounts of transfusion. For all those in between, we need a better definition of the indications and outcomes from bleeding and associated transfusion that can improve the balance between benefit and harm.

Observational literature suggests an association between perioperative bleeding severity during cardiac procedures and adverse outcomes, including infections, renal dysfunction, reoperations, and mortality. ${ }^{12}$ Likewise, preoperative anemia carries increased risks of mortality and serious morbidity. ${ }^{4,13}$ Evidence that supports the harms of anemia and transfusion lacks the rigor of multiple randomized trials, but large database studies provide some insight into the relationship among anemia, blood transfusion, and surgical outcomes. The combination of anemia and transfusion seems to be particularly bad, certainly worse than anemia or transfusion alone (Figure 4). ${ }^{14}$

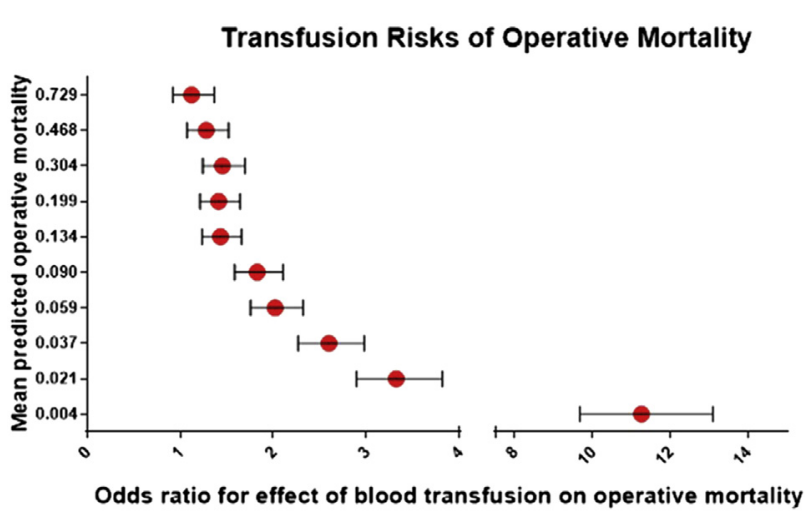

FIGURE 3. Transfusion-related odds ratio of operative mortality in a large group of surgical patients. ${ }^{4}$ 


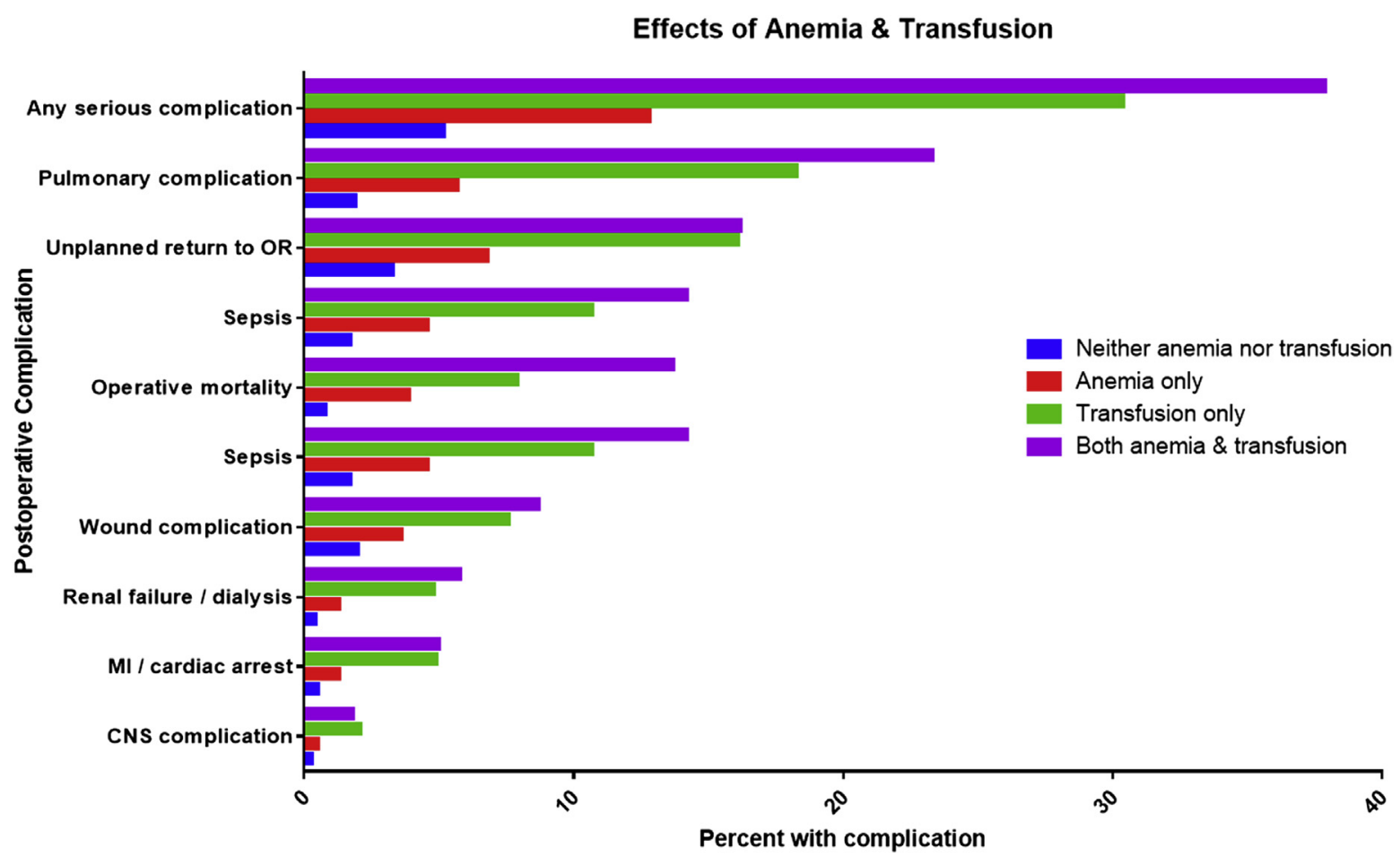

FIGURE 4. Effect of anemia and transfusion on surgical outcomes. ${ }^{14} O R$, Operating room; $M I$, myocardial infarction; $C N S$, central nervous system.

Postoperative treatment of patients undergoing cardiac operations is not well standardized. There are wide variations in triggers for postoperative interventions, especially transfusion. ${ }^{15}$ Likewise, there are variations in the responses to preoperative anemia in these patients. The typical distribution of transfusion seen in patients undergoing cardiac operations suggests that a minority of patients account for as much as $80 \%$ of all blood products transfused, whereas the majority of patients do not receive any transfusions. ${ }^{14}$ So if one were going to construct a scheme to limit bleeding and blood transfusion, one might choose to address the population who use the most blood products. For a variety of reasons, this high-risk group of patients who consume the greatest fraction of blood products are the hardest to study and probably the least likely to benefit from the typical blood conservation interventions outlined in Table 1.

There are a handful of interventions that may have some importance across the spectrum of bleeding and blood transfusion. It is worth describing some of these interventions and, more important, advocating for more investigation into the usefulness of these interventions in all parts of the bleeding spectrum, particularly the "high-end users." One example that stands out is the use of massive transfusion protocols. Because of the extreme urgency of transfusion need in patients with massive hemorrhage, most institutions have a massive transfusion protocol that is triggered by massive hemorrhage. An implicit part of this protocol management is point of care testing that provides early and accurate indications of transfusion needs. ${ }^{16}$ Technical reasons are at the root of most bleeding, emphasizing a major focus for process improvement to minimize bleeding and reoperation. ${ }^{17}$ Likewise, there is a strong association between nadir hematocrit during cardiopulmonary bypass and adverse bleeding-related outcomes. ${ }^{18}$ Because of the direct relationship between nadir hematocrit on cardiopulmonary bypass and preoperative anemia, investigations into the optimization of preoperative hematocrit for both elective and urgent/emergency operations are justified. In high-risk patients, a meta-analysis and a randomized trial found that strict goal-directed control of perioperative blood transfusion including standardized triggers leads to reduced major morbidity and less blood transfusion. ${ }^{19}$ The article by Ad and co-authors ${ }^{5}$ provides strong support for routine blood conservation interventions in averagerisk patients undergoing cardiac operations. More work needs to be done to address the entire spectrum of users of blood products, especially the small group of patients who consume the majority of blood products during cardiac procedures.

\section{References}

1. Loor G, Koch CG, Sabik JF III, Li L, Blackstone EH. Implications and management of anemia in cardiac surgery: current state of knowledge. J Thorac Cardiovasc Surg. 2012;144:538-46.

2. Loor G, Li L, Sabik JF III, Rajeswaran J, Blackstone EH, Koch CG. Nadir hematocrit during cardiopulmonary bypass: end-organ dysfunction and mortality. $J$ Thorac Cardiovasc Surg. 2012;144:654-62.e4.

3. Ferraris VA, Brown JR, Despotis GJ, Hammon JW, Reece TB, Saha SP, et al. 2011 update to the Society of Thoracic Surgeons and the Society of 
Cardiovascular Anesthesiologists blood conservation clinical practice guidelines. Ann Thorac Surg. 2011;91:944-82.

4. Gunn T, Paone G, Emery RW, Ferraris VA. The case for a conservative approach to blood transfusion management in cardiac surgery. Innovations (Phila). 2016; 11:157-64.

5. Ad N, Holmes SD, Patel J, Shuman DJ, Massimiano PS, Choi E, et al. The impact of a multidisciplinary blood conservation protocol on patient outcomes and cost after cardiac surgery. J Thorac Cardiovasc Surg. 2017;153:597-605.e1.

6. Holcomb JB, Tilley BC, Baraniuk S, Fox EE, Wade CE, Podbielski JM, et al. Transfusion of plasma, platelets, and red blood cells in a 1:1:1 vs a 1:1:2 ratio and mortality in patients with severe trauma: the PROPPR randomized clinical trial. JAMA. 2015;313:471-82.

7. Greilich PE, Edson E, Rutland L, Jessen ME, Key NS, Levy JH, et al. Protocol adherence when managing massive bleeding following complex cardiac surgery: a study design pilot. J Cardiothorac Vasc Anesth. 2015;29:303-10.

8. Sniecinski RM, Levy JH. Bleeding and management of coagulopathy. J Thorac Cardiovasc Surg. 2011;142:662-7.

9. Perel P, Clayton T, Altman DG, Croft P, Douglas I, Hemingway H, et al. Red blood cell transfusion and mortality in trauma patients: risk-stratified analysis of an observational study. PLoS Med. 2014;11:e1001664.

10. Ferraris VA. Blood transfusion balance: too much, not enough, or just right. J Thorac Cardiovasc Surg. 2014;148:3089-91.

11. Ferraris VA, Davenport DL, Saha SP, Austin PC, Zwischenberger JB. Surgical outcomes and transfusion of minimal amounts of blood in the operating room. Arch Surg. 2012;147:49-55.

12. Mariscalco G, Gherli R, Ahmed AB, Zanobini M, Maselli D, Dalen M, et al. Validation of the European Multicenter Study on Coronary Artery Bypass
Grafting (E-CABG) bleeding severity definition. Ann Thorac Surg. 2016;101: 1782-8.

13. Padmanabhan H, Aktuerk D, Brookes MJ, Nevill AM, Ng A, Cotton J, et al. Anemia in cardiac surgery: next target for mortality and morbidity improvement? Asian Cardiovasc Thorac Ann. 2016;24:12-7.

14. Ferraris VA, Hochstetler M, Martin JT, Mahan A, Saha SP. Blood transfusion and adverse surgical outcomes: the good and the bad. Surgery. 2015;158: 608-17.

15. Bennett-Guerrero E, Zhao Y, O'Brien SM, Ferguson TB Jr, Peterson ED, Gammie JS, et al. Variation in use of blood transfusion in coronary artery bypass graft surgery. JAMA. 2010;304:1568-75.

16. Deppe AC, Weber C, Zimmermann J, Kuhn EW, Slottosch I, Liakopoulos OJ, et al. Point-of-care thromboelastography/thromboelastometry-based coagulation management in cardiac surgery: a meta-analysis of 8332 patients. J Surg Res 2016;203:424-33.

17. Vivacqua A, Koch CG, Yousuf AM, Nowicki ER, Houghtaling PL, Blackstone EH, et al. Morbidity of bleeding after cardiac surgery: is it blood transfusion, reoperation for bleeding, or both? Ann Thorac Surg. 2011;91: 1780-90.

18. Habib RH, Zacharias A, Schwann TA, Riordan CJ, Durham SJ, Shah A Adverse effects of low hematocrit during cardiopulmonary bypass in the adult: should current practice be changed? J Thorac Cardiovasc Surg. 2003;125: $1438-50$.

19. Osawa EA, Rhodes A, Landoni G, Galas FR, Fukushima JT, Park CH, et al Effect of perioperative goal-directed hemodynamic resuscitation therapy on outcomes following cardiac surgery: a randomized clinical trial and systematic review. Crit Care Med. 2016;44:724-33. 